\title{
HIV - 2 infections from a tertiary care hospital in India - a case report
}

\begin{abstract}
HIV-1 has spread globally, whereas HIV-2 has mostly remained limited to West Africa. India is one of the countries where a dual epidemic of HIV $1 \& 2$ is occurring. There are several reports indicating presence of HIV-2 infection in India. First case of HIV-2 in India was reported from Mumbai, in 1991. Since then it has been identified from geographically diverse states, yet reliable data regarding HIV-2 epidemiology in India is still lacking. According to some studies, the prevalence of HIV in various parts of India is different. It is particularly high in the western and the southern parts. In western India, HIV-2 and dual infections with HIV-1 and HIV-2 have been reported since early nineties and in South India in late nineties. The following is a report of a case of HIV-2 infection from a tertiary care hospital in North India.
\end{abstract}

Volume 5 Issue 4 - 2017

\author{
Malhotra S, Dhundial R, Bhatia NJK, Duggal \\ N \\ Department of Microbiology, PGIMER and Dr RML Hospital, \\ India
}

Correspondence: Malhotra S, Department of Microbiology, PGIMER and Dr RML Hospital, New Delhi, India,

Email drshalinimakhotra@yahoo.com

Received: March 31, 2017| Published: May 08, 2017

Keywords: HIV- 2, Human Immunodeficiency Virus, Prevalence

\section{Introduction}

Approximately 2.1 million people are currently living with HIV AIDS in India. ${ }^{1}$ In 1986, the first case of HIV infection in India was detected among sex workers in Chennai. ${ }^{2}$ In the same year, HIV-2 was isolated from AIDS patients in West Africa. ${ }^{3}$ The first evidence of HIV-2 infection in India was provided in $1991 .{ }^{4}$ Since then it has been sporadically reported from various states of India. HIV-2 appears to be transmitted principally by sexual contact, with prostitutes being the well-studied group. The virus can also be spread by blood transfusion of infected blood. Compared to HIV-1, transmission of HIV-2 virus from an infected mother to her child seems to be less frequent. However, cases of transmission from an infected woman to her fetus have been reported among women who had primary HIV2 infection during their pregnancy. ${ }^{5}$ The prevalence rate of HIV-2 infection in India is not available so far. The following is a report of HIV-2 infection from Delhi in North India.

\section{Case report}

A 45 year - old laborer presented to an integrated counseling and testing centre (ICTC) as a direct walk-in for HIV testing in July 2016 with unexplained chronic diarrhea for longer than one month and generalized weakness. The patient was a resident of Delhi and stayed with his spouse. The patient gave a history of frequent contacts with commercial sex workers (CSW). Following the guidelines of the National AIDS Control Organization (NACO), after informed consent and pre-test counseling, his blood sample was tested for HIV using a rapid test (Comb Aids, J Mitra, Delhi) following manufacturer's instructions. Test was reactive for HIV, following which two more rapid tests (SD Bio line; Aids scan Tri-spot) were carried out on the same sample (one test was able to differentiate between HIV-1 and 2). The sample was reactive on all three tests and was further confirmed by Western blot. The patient was found to be HIV-2 positive and was registered with the anti-retroviral therapy (ART) Centre. Since the patient gave a history of regular unprotected sex with his spouse, we suggested the wife to be tested for HIV. She was found to be negative for HIV as per NACO guidelines. His CD4 T-cell count was 266 $(22 \%)$ cells $/ \mathrm{mm} 3$ and did not have any other significant laboratory abnormality. His other autoimmune profile was normal.

\section{Discussion}

Although HIV-2 infection is mostly confined to West African countries it has been identified in other continents following sexual contact with foreigners with a history of frequent contact with CSWs, as in our case. ${ }^{6}$ These CSWs provide a bridge for transferring HIV2 infection from high prevalence regions, such as West African countries, to low prevalence countries, such as India. Sequential serological surveys from a Hospital population in Tamil Nadu during 1993-97 and 2000-01 showed a stable HIV-2 prevalence over time, at $2.47 \%$ of all HIV diagnoses. ${ }^{7}$ The frequency of HIV-2 in a blood donor population at a tertiary referral hospital in Southern India between the period $1998-2007$ was also similar at $2.8 \%$ of all HIV diagnoses [ $1.3 \% \mathrm{HIV}-2$ and $1.5 \%$ HIV $1 \& 2$ dual infections]. ${ }^{8}$ Various studies from South and West India has reported that HIV-2 prevalence ranges from $0.3-2.1 \%{ }^{5,9,10}$ Murugan and Amburajan observed a prevalence of $0.29 \%$ of HIV-2 in south Tamil Nadu, and Solomon et, al. reported a prevalence rate of $0.9 \%$ with HIV-2 among urban population $^{11,12}$ There are various reports of HIV - 2 infection from South India but data from North India is much limited. It was seen that more discordant couples exist with HIV-2 infection than HIV-1 infection as was seen in our case and his spouse in spite of having regular unprotected sex. Reason being that compared to HIV-1, those with HIV-2 are less infectious early in the course of infection. ${ }^{13,14}$ No guidelines regarding the clinical treatment and care of patients infected with HIV-2 are available yet. As we know that HIV-2 virus is intrinsically resistant to NNRTI and to enfluvirtide and some protease inhibitors are also ineffective, the treatment options are limited. It is also not known whether any potential benefits would outweigh the possible adverse effects of treatment. Estimation of HIV-2 viral load assays is another major problem with no commercially available assay. Viral load assays used for HIV-1 are not reliable for monitoring HIV-2. Therefore, monitoring the treatment response of patients infected with HIV-2 is more difficult than monitoring people infected with HIV-1. There is need to standardize, validate, and commercialize simple, low-cost HIV-2 viral load assays. The only option available to monitor the response to treatment for HIV-2 infection is by secondary parameters like CD4+T-cell counts and other indicators of immune system deterioration such as weight loss, oral candidiasis, unexplained fever, and the appearance of a new AIDS defining illness. To determine the most effective treatment for HIV-2, more efforts in terms of 
research are needed. We need the exact prevalence and incidence of HIV-2 infection in our country to establish proper guidelines and different regimens for management of HIV-2. Otherwise, it is possible to have serious resistant strains of HIV-2 which will possibly pose a problem in our country in the future as the present regimen given in government anti retroviral therapy (ART) centers is not highly active ant - retroviral therapy (HAART). In conclusion, continued surveillance is needed to monitor for and develop special guidelines for HIV-2 in the Indian population. Physicians involved in screening for HIV need to have a high index of suspicion in patients with risk factors for HIV-2 infection, to appropriately diagnose and treat the disease since these patients develop AIDS - related symptoms late due to delayed progression. Guidelines should be created for HIV testing of spouses with HIV-2 infection to diagnose and treat the disease, since these cases have inefficient transmission.

\section{Acknowledgments}

None.

\section{Conflicts of interest}

None.

\section{References}

1. HIV and AIDS estimates, UNAIDS. USA. 2015

2. Simoes EA, Babu PG, John TJ et al. Evidence for HTLV-III infection in prostitutes in Tamil Nadu (India) Indian J Med Res. 1987;85:335-338.

3. Clavel F, Guetard, D et al. Isolation of HIV type 2. Science. 1987;223:343-346.

4. Rübsamen-Waigmann H, Briesen HV, Maniar JK et al. Spread of HIV-2 in India. Lancet 1991;337(8740):550-551.
5. Agrawal S, Sawant S, Shastri J Prevalence of HIV-2 infection in Mumbai. Indian J Dermatol Venereol Leprol. 2010;76(6):709-710.

6. Leaño PS, Kageyama S, Espantaleon A et al. Introduction of human immunodeficiency virus type 2 infection in the Philippines. $J$ Clin Microbiol. 2003;41(1):516-518.

7. Kannangai R, Ramalingam S, Vijayakumar TS et al. HIV-2 subepidemic not gathering speed: experience from a tertiary care center in South India. J Acquir Immune Defic Syndr. 2003;32(5): 573-575.

8. Kannangai R, Nair SC, Sridharan G, et al. Frequency of HIV type2 infections among blood donor population from India: a 10-year experience. Indian J Med Microbiol. 2010;28(2):111-113.

9. Chiara M, Rony Z, Homa M, et al. Characteristics, immunological response and treatment outcomes of HIV-2 compared with HIV-1 \& dual infections (HIV 1/2) in Mumbai. Indian J Med Res. 2010;132:683-689.

10. Sonth SB, Solabannavar SS, Baragundi MC, et al. The prevalence of HIV-2 seropositivity in blood donors. $J$ Clin Diagn Res. 2010;4(5):3091-3094.

11. Murugan S, Amburajan R. Prevalence of HIV-2 infection in South Tamil Nadu. Indian J Sex Transm Dis. 2007;28(2):1-113.

12. Solomon S, Kumarasamy N, Ganesh AK, et al. Prevalence and risk factors HIV-1 and HIV-2 infections in urban and rural areas in Tamil Nadu, India. Int J STD AIDS. 1998;9(2):98-103.

13. Andersson S, Norrgren H, da Silva Z, et al. Pasma viral load in HIV-1 and HIV-2 singly and dually infected individuals in Guinea-Bissau, West Africa significantly lower plasma virus set point in HIV-2 infection than in HIV-1 infection. Arch Intern Med. 2000;160(21):3286-3293.

14. Popper SJ, Sarr AD, Guèye-Ndiaye A, et al. Low plasma human immunodeficiency virus type 2 viral load is independent of proviral load: low virus production in vivo.J Virol. 2000;74(3):1554-1557. 